\title{
Modeling of Hydrodynamic Processes in Diesel Injector Nozzle
}

\author{
O. VRUBLEVSKYI*, D. LEVCHENKO** \\ *University of Warmia and Mazury in Olsztyn, Poland, E-mail: aleksander.wroblewski@uwm.edu.pl \\ **Kharkiv Automobile and Highway University, Ukraine, E-mail: dvs@khadi.kharkov.ua

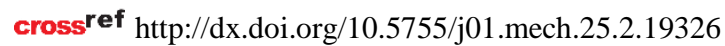

\section{Introduction}

The diesel injector nozzle is a final element of the fuel injection line of the diesel engine and greatly affects the process of spraying, the nature and the quality of the injection, the hydraulic flow resistance. Investigation of hydrodynamic processes in the spray channels is a very difficult task due to the small size of the flowing channels $(0.1-3 \mathrm{~mm})$ and the short time period of the injection process $(0.1-3 \mathrm{~ms})$. Modern requirements to diesel fuel system is increasing injection pressure that changes fuel injection characteristics.

A perspective and topical task is analytical calculation of the nozzle cavity by the finite volume method with the aid of special advanced software, which allows to create a three-dimensional visual model of the flow process in the atomizer. Such calculations with a high degree of accuracy allow us to estimate the physical parameters of the fuel flow, make it possible to carry out a relatively quick and convenient investigation with wide ranges of variables of initial parameters. It is a necessary step in the process of designing and reconstructing the design of the nozzle.

\section{Analysis of references}

The average lifetime of even the most advanced designs of a spray nozzle for diesel engines is $150 \ldots 180$ thousand $\mathrm{km}$. car mileage, which significantly reduces the overall resource of the power system and the engine as a whole. Given the trends in the automotive industry, today it is necessary to have a resource of about 500 thousand $\mathrm{km}$. It gives to designer the task of increasing the reliability of the most vulnerable elements of the diesel injectors: friction pairs, injector cone seat, nozzle holes and injector nozzle tip [1-5].

Construction of the diesel injector nozzle has a variety of disadvantages, which is mainly depends on the complexity of the technological process of its manufacture. Work in difficult conditions under the influence of high pressures and temperatures, cyclic loads, aggressive environment often becomes a reason for failure of the fuel system.

Besides, the perfection of the nozzle design and its integrity determines the injection process and thus the combustion quality and formation of harmful substances in the exhaust gases (unburned hydrocarbons $\mathrm{CH}$, soot, and nitrogen oxides NOx) $[6,7]$.

To investigate the hydrodynamic phenomena in the nozzle, it is necessary to apply the world experience [7-11] of using numerical experiment by using numerical calculation of hydrodynamics or CFD (Calculation Fluid Dynamic) that are implemented in special software complexes. To perform this task, the AVL FIRE 2013 software was chosen, which completely corresponds to the modern level of hydrodynamic processes simulation. In the works $[8,10,11]$ is given a calculation methods of similar problem of the nonstationary turbulent flow in the flow part of the injector nozzle, considering the two-phase flow, which was used as the basis for setting up the own experiment.

\section{The purpose and formulation of the problem}

The purpose of the research is to analyze the complex hydrodynamic processes occurring in the fuel flowing cavities, slits and injection nozzle orifices in the nozzle of the high-speed diesel engine 4DTNA1. To perform this, the following tasks must be solved:

- to create a nozzle calculation mesh, determine initial parameters and boundary conditions of the simulation;

- calculate the hydrodynamic processes in the flow parts of the nozzle;

- to carry out an analysis of the flow inside and at the outlet border of nozzle.

- identify the arias of the resistance of the flow, pressure loss, excessive turbulence of the flow, liquid and vapor phase separation and the emergence of the cavitation effect;

- specify ways to improve the flow characteristics in the nozzle by optimizing the geometry of the flow path.

\section{Modeling methodology}

Initial data for the calculation were being obtained during processing results of research of the fuel equipment of diesel engine 4DTNA1 [12]. Pressure data in the highpressure fuel line, the needle lifting and fuel parameters were used as boundary conditions in the simulation. Main parameters are presented in Table 1.

Table 1

Boundary conditions for calculation

\begin{tabular}{|c|c|}
\hline Parameter & Value \\
\hline Pressure in the system of fuel supply, MPa & 80 \\
\hline Pressure in cylinder while injection, $\mathrm{MPa}$ & 12 \\
\hline Heel lifting needle, $\mathrm{mm}$ & 0,25 \\
\hline Diameter of nozzle orifice, $\mathrm{mm}$ & 0,2 \\
\hline Length of nozzle orifice, $\mathrm{mm}$ & 1 \\
\hline Angle of axis of nozzles, deg & 54 \\
\hline
\end{tabular}

The simulation was performed on the geometric model of the nozzle tip flow path of the, which includes injector cone seat, needle tip, nozzle sac and nozzle orifice. For the purposes of numerical simulation, spatial calculation grids were created by the internal features of AVL FIRE.

Works $[11,13,14]$ is the most correspond to our investigation and compare different approach for modeling 
cavitation phenomena in fuel flow which gives adequate result to real flow according to [14, 15]. AVL FIRE advanced cavitation two-phase flow model. It is based on general flued flow theory by Navier-Stokes derivative equations. Feather is shown the principal shape of main set of equations that should be solved for each phase (liquid and vapor) separately to define their volume rate of each and their transformation.
Mass conversation (Continuity Equation):

$$
\frac{\partial \rho}{\partial t}+\frac{\partial}{\partial x_{i}}\left(\rho u_{i}\right)=0
$$

Conservation of Momentum (Equation of Motion):

$$
\rho \frac{\partial u_{i}}{\partial t}+\rho u_{j} \frac{\partial}{\partial x_{i}}\left(u_{i}\right)=-\frac{\partial p}{\partial x_{i}}+\frac{\partial}{\partial x_{j}} \times\left[\mu\left(\frac{\partial u_{i}}{\partial x_{i}}+\frac{\partial u_{i}}{\partial x_{j}}-\frac{2}{3} \delta_{i, j} \frac{\partial u_{l}}{\partial x_{l}}\right)\right]+\frac{\partial}{\partial x_{j}}\left[-\rho \overline{u_{i}^{\prime} u_{j}^{\prime}}\right]
$$

Turbulence flow modelling include turbulence energy transport equation:

$$
\frac{\partial(\rho k)}{\partial t}+\frac{\partial}{\partial x_{i}}\left(\rho u_{i} k\right)=\frac{\partial}{\partial x_{i}}\left[\left(\mu+\frac{\mu_{t}}{\sigma_{k}}\right) \frac{\partial k}{\partial x_{i}}\right]-\rho \overline{u_{i}^{\prime} u_{j}^{\prime}} \frac{\partial u_{j}}{\partial x_{j}}-\rho \varepsilon,
$$

and equation of dissipation of turbulence energy:

$$
\frac{\partial(\rho \varepsilon)}{\partial t}+\frac{\partial}{\partial x_{i}}\left(\rho u_{i} \varepsilon\right)=\frac{\partial}{\partial x_{i}}\left[\left(\mu+\frac{\mu_{t}}{\sigma_{\varepsilon}}\right) \frac{\partial k}{\partial x_{i}}\right]-C_{1 \varepsilon} \frac{\varepsilon}{k} \rho \overline{u_{i}^{\prime} u_{j}^{\prime}} \frac{\partial u_{j}}{\partial x_{j}}-C_{1 \varepsilon} \rho \frac{\varepsilon^{2}}{k},
$$

where: $t$ is the time; $\rho$ is the density; $x$ is the coordinate; $i, j$, $l$ are indexes; $u$ is the time-averaged velocity; $\mu$ is the dynamic viscosity of the liquid; $\mu_{t}=\rho C_{\mu} \frac{k^{2}}{\varepsilon}$ is the turbulent viscosity; $p$ is the time-averaged pressure; $\delta_{i, j}$ is the Kronecker delta;

$\overline{u_{i}^{\prime} u_{j}^{\prime}}=\mu\left(\frac{\partial u_{i}}{\partial x_{i}}+\frac{\partial u_{i}}{\partial x_{j}}-\frac{2}{3} \delta_{i, j} \frac{\partial u_{l}}{\partial x_{l}}\right)-\frac{2}{3} k \rho \delta_{i, j} \quad$ is the time-averaged product of the pulsating components of the projections of velocities on the coordinate axes; $C_{\mu}, C_{1 \varepsilon}, C_{2 \varepsilon}$, $\sigma_{k}, \sigma_{\varepsilon}$ are constants.

AVL FIRE allows to consider influence of cavitation phenomena on the canal surface stress by using advanced Erosion Model [16]. It based on the Relay-Plesset equation, which calculates the dynamics of the bubble pair growth.

$$
R_{b} \frac{d^{2} R_{b}}{d t^{2}}+\frac{3}{2}\left(\frac{d R_{b}}{d t}\right)^{2}+\frac{2 \sigma}{\rho_{f} R_{b}}=\frac{p_{s v}-p_{f b}}{\rho_{f}},
$$

where: $R_{b}$ is the radius of bubble of pair; $\sigma$ is the surface tension ratio between fluid and its vapor; $p_{s v}$ is the saturated vapor pressure; $p_{f b}$ is the fluid pressure round the bubble; $\rho$ is the liquid density.

The mass change between the liquid and the steam is calculated by the level of vaporization:

$$
\dot{m}_{\text {evap }}=F_{\text {evap }} \frac{3 a_{v . f o r m}\left(1-a_{v}\right) \rho_{v}}{R_{v}} \sqrt{\frac{2}{3} \frac{p_{s v}-p_{f}}{\rho_{f}}} .
$$

Condensation equation:

$$
\dot{m}_{\text {cond }}=F_{\text {cond }} \frac{3 a_{p} \rho_{p}}{R_{p}} \sqrt{\frac{2}{3} \frac{p_{s v}-p_{f}}{\rho_{f}}} .
$$

where: $\dot{m}_{\text {evap }}$ and $\dot{m}_{\text {cond }}$ are transfer of mass per volume units due to vapor formation and condensation; $a_{v, f o r m}$ and $a_{v}$ are the volume fraction of vapor formation and pair; $F_{\text {evap }}$ and $F_{\text {cond }}$ are dimensionless coefficients.

To bring the task closer to the real conditions of the injection process, were performed a series of sequential calculations with variable geometry of the model for simulation motion of the needle with certain function. The nonstationary process greatly increases the amount of calculations, but gives a complete understanding of the fuel flow conditions during all injection time.

\section{Nozzle geometry improvement}

The main parameter for estimating injector's nozzles is their hydraulic characteristic, which shows the dependence of the nozzle opening pressure on nozzle flow rate. This parameter depends entirely on the geometry of the flow pass parts of the nozzle, namely the orifice holes: the injector cone seat (the ratio of the angles of the needle and nozzle cones) and nozzle orifice of the spray $[9,11,13,17]$.

The geometrical parameters of the nozzle flow pass, that have the most significant influence on the hydraulic characteristics are listed below:

- diameter of nozzle holes and their length;

- diameter of the nozzle sac, its volume and shape;

- angle of nozzle orifice inclination to the axis of the needle movement;

- the ratio of the angles of the needle and nozzle cones; needle tip length and geometry. 


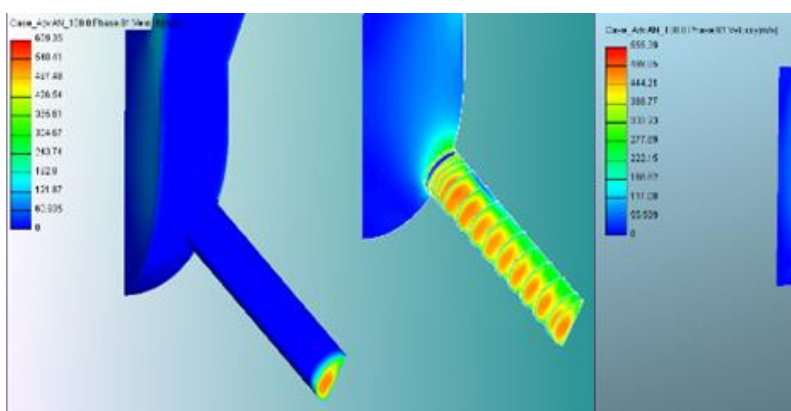

a

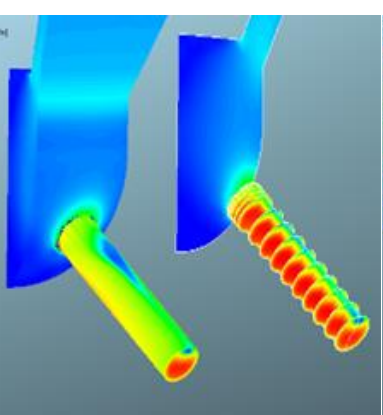

b

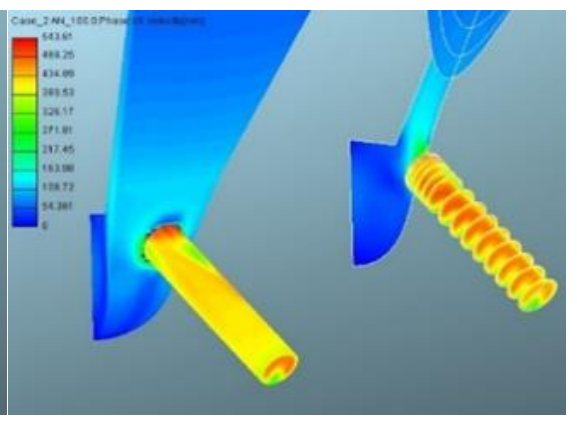

C

Fig. 1 Velocity in the holes truncated by symmetry plane (a) and complete nozzle hole (b, c)

To improve the flow rate of sprayers while maintaining high-quality of spraying it is possible to smooth out the entrance edge of the nozzle, to give the nozzle orifices the conical shape with a narrowing to the end, to design the nozzle orifice axes along the flow direction, to reduce the nozzle sac volume or to trim the edge of the nozzle seat cone in the edge of the smallest diameters [9, 7, 11, 13, 17].

The easiest way to achieve several of the proposed measures at once - drilling nozzle holes directly onto the nozzle seat cone below the needle seating contact. Such design is considered perspective in [10-13].

Further, to compare the existing and proposed designs of nozzles, we will give the calculation results of the both models and will note the important differences if necessary. On the left there will be an existing model with a distinct sac (hereinafter "FIRST"), on the right - with a drill on the cone (hereinafter "SECOND").

\section{Consideration of the fuel injection calculation results}

The first received results of calculation were inappropriate realistic flow in the nozzle, probably because of the using simplified model with the symmetry plane along the axis of the opening (Fig. 1a). There was separation of the flow inside orifice, the decision to use further the segment, which completely covers the volume of nozzle hole (Fig. $1 \mathrm{~b}, \mathrm{c}$ ). This should greatly increase the quality of the calculation model and the accuracy of the calculation results.

As a result, of the calculation, we have received many instantaneous local parameters of the fuel flow in the nozzle at certain phase of injection. For analysis behavior of the flow, we will use the following parameters: speed $[\mathrm{m} / \mathrm{s}]$, direction (line of flow), pressure [MPa], turbulent kinetic energy, $\left[\mathrm{m}^{2} / \mathrm{s}^{2}\right]$ volume fraction of pair phase [\%], cavitation erosion speed [nm/hour].

Fig. 2 shows calculations of local fuel flow velocities in the nozzle sac and hole. It shows that in the area of the entrance edge of the hole in its upper part (in the SECOND model) there is a hydraulic resistance. As a result, the flow rate is reduced by 4 times the maximum level in the nozzle orifice. Zone of reduced speed is stored during the whole process of fuel injection.

To eliminate this phenomenon, it is necessary to reduce the angle of change the flow direction or to smooth out the entrance edge of the nozzle with a radius of not less than $0.03 \mathrm{~mm}$.

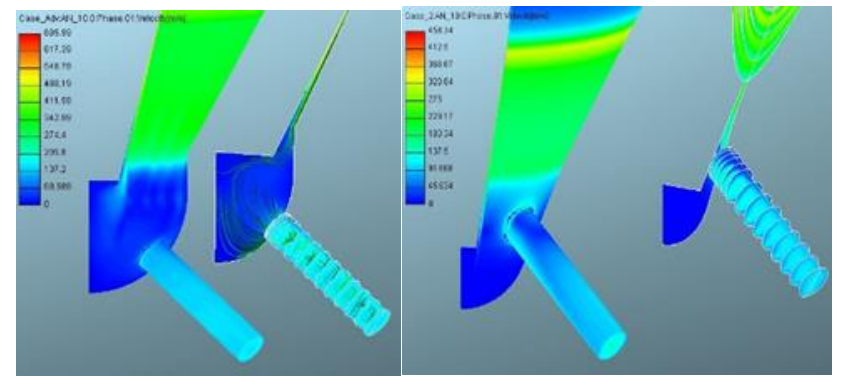

a

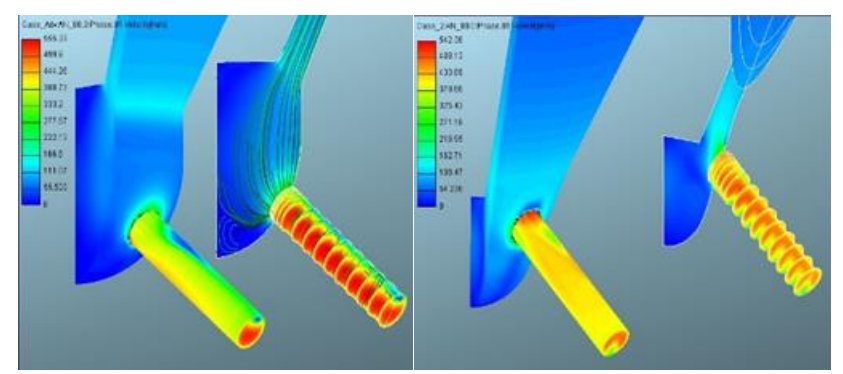

b

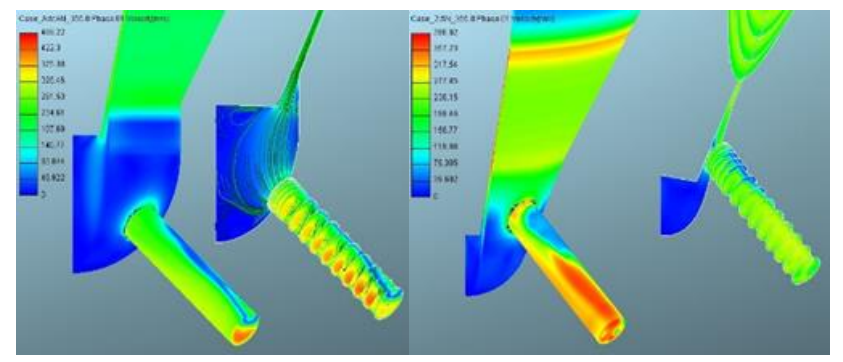

c

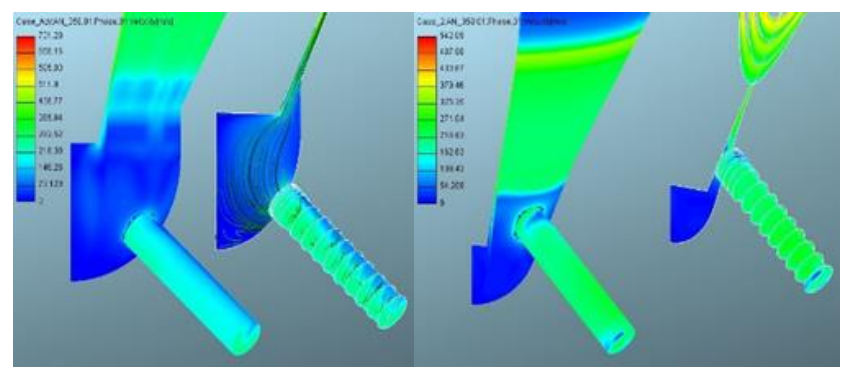

d

FIRST

SECOND

Fig. 2 Flow rate during fuel injection: a - begin of needle movement (needle lift - $0.02 \mathrm{~mm}$ ); b - full open nozzle $(0.25 \mathrm{~mm})$; c - end of injection $(0.04 \mathrm{~mm})$; $\mathrm{d}$ - closing nozzle $(0.005 \mathrm{~mm})$ 
The scales at corresponding needle position of models are similar (in average $0-500 \mathrm{~m} / \mathrm{s}$ ) so the results could be compared visually. Comparing the results of the speed calculation for both models it can be noted that the FIRST model has more uniform and stable injection, which reduces the risk of leaking fuel and as the result gumming the hole. By the way SECOND model has $50-70 \mathrm{~m} / \mathrm{s}$ less velocity that show better flow rate and lead to prolong good atomization injection period. At the time of full injector opening the SECOND geometry allow to normalize boundary flow in injection orifice unlike the FIRST one which reduce the useful orifice cross-sectional area. By narrowing down the axes of injection holes to injector axe is possible to reduce this phenomenon for both geometries.

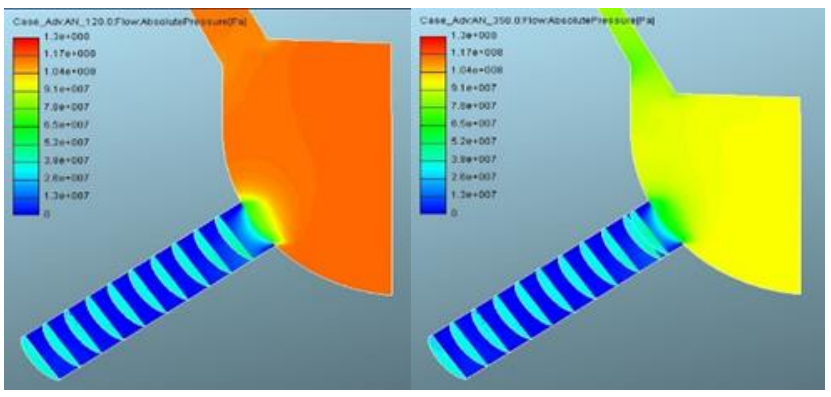

$\mathrm{a}$

b
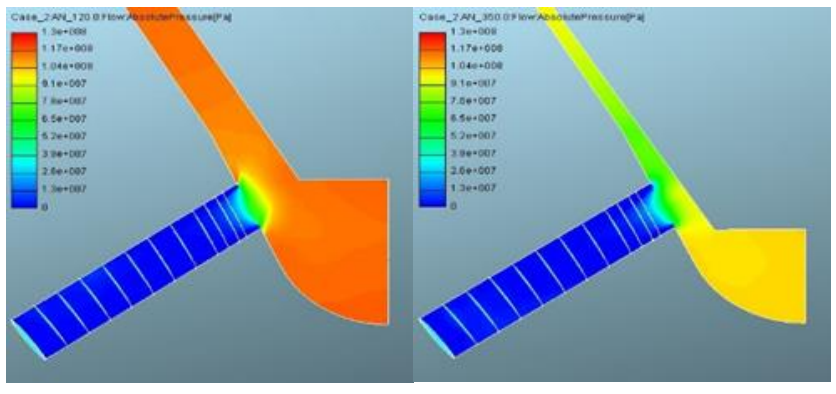

C

d

Fig. 3 Pressure loss in nozzle orifice: a - FIRST model max flow rate (needle lift $-0.25 \mathrm{~mm}$ ); $\mathrm{b}$ - FIRST model min flow rate $(0.005 \mathrm{~mm})$; c - SECOND model max flow rate $(0.25 \mathrm{~mm}) ; \mathrm{d}-\mathrm{SECOND}$ model min flow rate $(0.005 \mathrm{~mm})$

One of the most important parameters of the injection is the injection pressure, that is, the pressure in the end of the nozzle orifice. This is a direct parameter of the injection and quality of fuel atomization. Due to the appreciable resistance of the flow to the entrance edge of the nozzle orifice, the injection pressure is much less than the pressure in the sac. The task of the designer to minimize this resistance to achieve a larger outlet flow rate and the best atomization. Also important is the pressure in nozzle orifice at the beginning of the needle movement and at the end of it because it can lead to the formation of droplets on the walls of the hole and lead to their gumming. Therefore, you need to strive to increase the injection pressure throughout the fuel cycle. On the other hand, the pressure in the sac should not exceed the maximal strength of the least normal cross-section area of the nozzle tip, which is weakened by the presence of nozzle holes.

Fig. 3 shows the results of calculating the pressure at the time of full the needle lifts up and at the time of its partial closing for the FIRST and the SECOND models, respectively. Analyze the results of calculating local pressures can conclude the most influential causes of the loss of pressure and analyze possible solutions to reduce them.

Aligning the scale, you can see a slight improvement of the pressure conditions before injector hole for SECOND model at the end of injection (d). It occurs due to less volume for expansion. At the full needle lift $(a, d)$ the pressure loses in the orifices of both models are almost identical.

In Fig. 4 it is evident that in the volumes at the end of the needle and at the bottom of the sac there is a whirling flow, which also affects the inhibition of the flow velocity due to internal friction in the liquid.

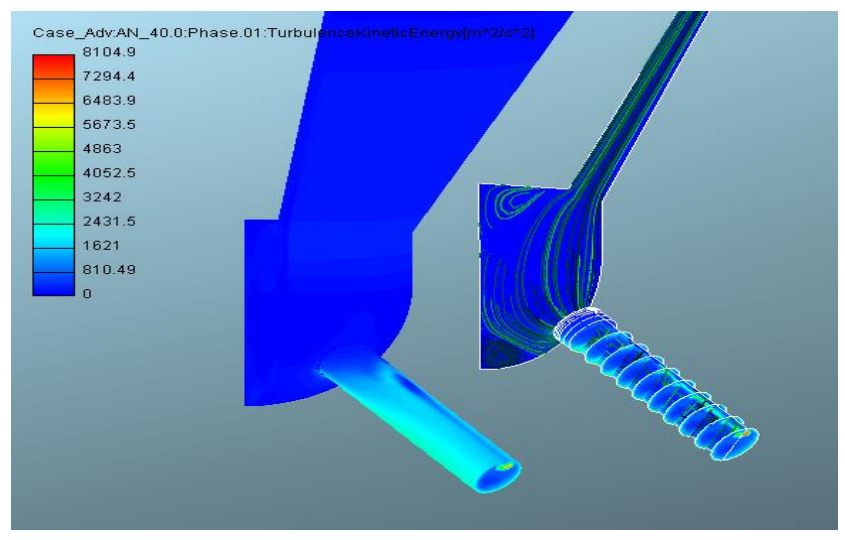

Fig. 4 Turbulent flow and whirling flow

In Fig. 4 is shown an example of flow turbulence that occurs in places of significant velocity gradients and to a greater extent occurs in the boundary layers of the nozzle hole. The turbulent motion of the boundary layers affects the time of establishing the normal injection process.

Another important factor, which is an indicator of the cavitation phenomenon on the surface of the shutter cone and nozzle holes and causes gradual wear of surfaces due to the staining of microparticles of a metal (Fig. 5). It occurs because the separation of the vapor phase from the liquid during a high local vacuum and next collapsing of vapor bubbles on the walls surfaces. As the calculation result, it is possible to estimate the zone and the relative volume of the vapor phase Fig. 5 shows how the volumes of both phases are distributed in the stream in such a way that the vapor phase separation takes place in the upper part of the nozzle orifice, which narrows the actual flow intersection of the main stream and reduces the flow factor of the nozzle [18].

The SECOND model is more prone to the phase separation in the orifice flow, but in this case, at the length of the nozzle holes, at the FIRST model $100 \%$ of the vapor fraction reaches the exit from the nozzle, reduces the flow rate of the nozzle, and worsen atomization condition. In the SECOND model the flow manages to rejoin the walls and denseness of outflow remain coinstantaneous. An advanced cavitation model for calculating the flow in a nozzle can provide a quantitative differential indicator of cavitation wear of the washed walls. This indicator is the rate of penetration of erosion into the surface $[11,17-22]$. The results of cavitation modeling are shown in Fig. 6.

Thus, due to the greater volume of vapor phase producing in the nozzle, the SECOND model is loaded with cavitation erosion phenomenon in 1.5-2 times higher than the FIRST one. 


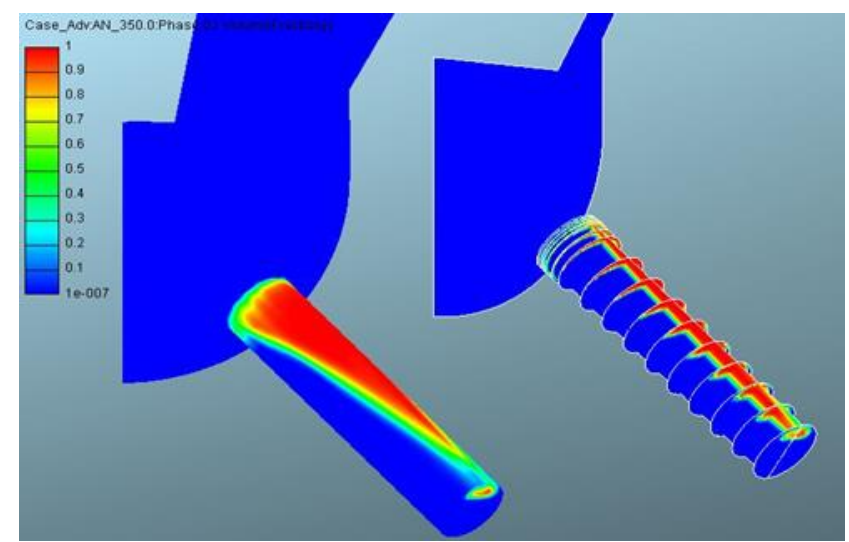

a

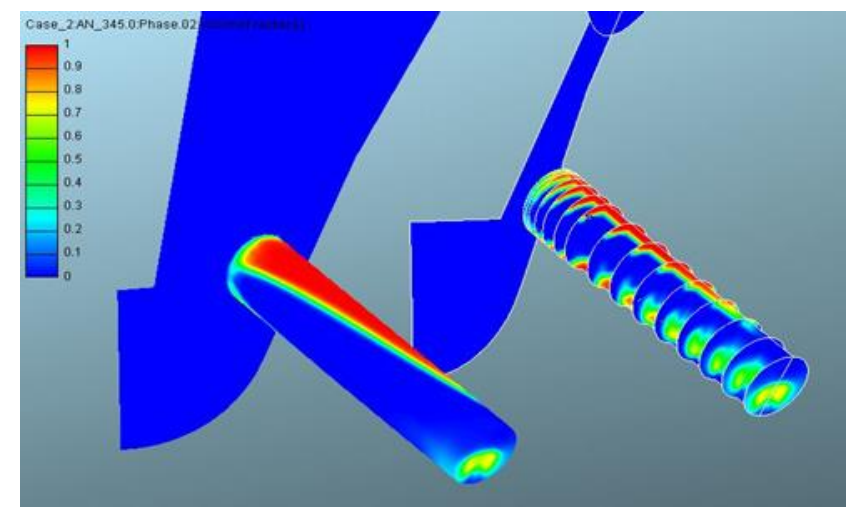

b

Fig. 5 Vapor phase volumetric fraction for the FIRST (a) and SECOND (b) models

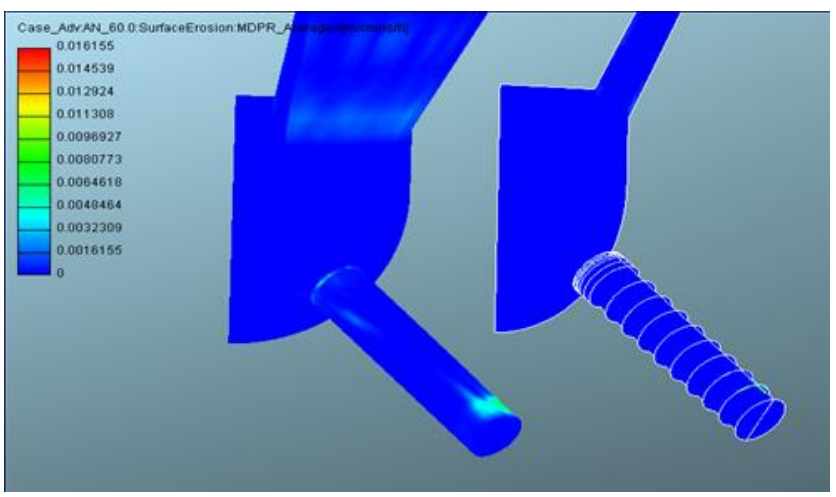

$\mathrm{a}$

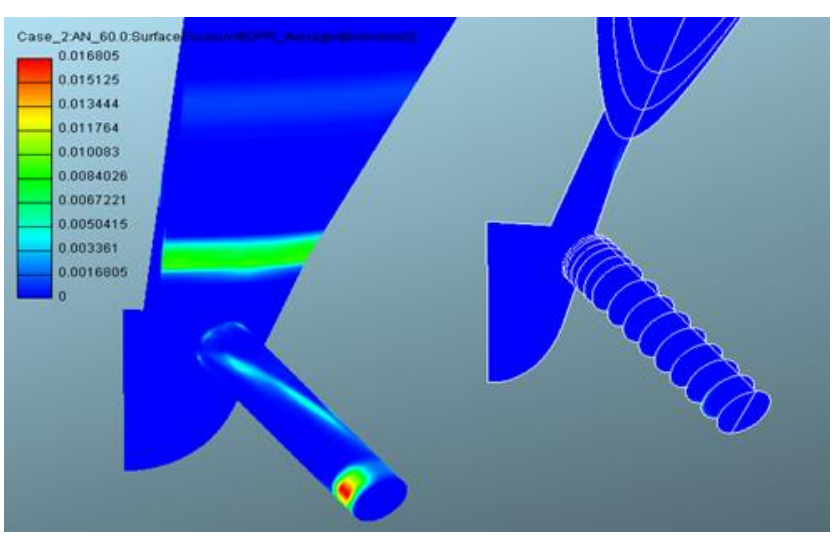

$\mathrm{b}$

Fig. 6 Mean depth of penetration rate for the FIRST (a) and SECOND (b) models

\section{Conclusions}

In the space of AVL FIRE, a fuel flow models have been created in the nozzle of the diesel engine 4DTNA1 when it is fed into a cylinder. The study of fuel flow inside diesel injector nozzle, which accompany the fuel supply, has been conducted. The simulation had been carried out by using AVL FIRE program for three-dimensional formulation of the problem. CFD simulation of real flow processes were performed by internal AVL FIRE advanced calculation model that allow taking in account two phases compressible fluid turbulent flow. The results of calculation of fuel flow for two variants of nozzle holes' arrangement have obtained.

The greatest loss of pressure in the flow is observed in the peripheral zone of the nozzle at the entrance edge and has a variable value of length from 0.1 to $0.3 \mathrm{~mm}$. To eliminate this phenomenon, it is necessary to smooth out the entrance edge of the nozzle with a radius of not less than 0.03 $\mathrm{mm}$. Also, due to abrupt change of the flow direction in the upper layers of the flow in the nozzle are more vacuum. To reduce the pressure difference in the section of the nozzle, it is possible to adjust the angle of its inclination to the axis of the needle movement.

To improve the flow conditions in the injector cone seat it is possible to make a sharp tip of the needle cone. At the time when needle lowering in the nozzle sac large values of the turbulent kinetic energy occur. Reducing the volume of the sac or creating displacing needle tip cone will decrease the turbulization of the flow and related problems of nozzle leakage and increasing of additional force of cavitation erosion on the walls of nozzle holes.

The calculation results allow simulate the process of formation and distribution of cavitation processes in the nozzle hole. Calculation shows that used for calculation geometry in certain local zones of nozzle holes the rate of erosion wear can reach values of $8 \mathrm{~nm} /$ hour, which lead to impairment of fuel spray quality.

Comparing the fuel flow parameters of both geometries was found out that variant with drilling the orifices on the cone gives enhancement of flow condition and provides better organization of fuel injection and atomization. On the other hand, the level of cavitation erosion for this geometry is higher.

\section{References}

1. Bai, Y.; Fan, L.Y.; Ma, X.Z.; Peng, H.L.; Song, E.Z. 2016. Effect of injector parameters on the injection quantity of common rail injection system for Diesel engines, International Journal of Automotive Technology 17(4): 567-579. https://doi.org/10.1007/s12239-016-0057-2.

2. Jiping, L.; Shuiyuan, T.; Yong, Z.; Jing, H.; Zhonghua, J. 2011. Simulation of assembly tolerance and characteristics of high pressure common rail injector, International Journal of Computational Intelligence Systems 4(6): 1282-1289. https://doi.org/10.1080/18756891.2011.9727877.

3. Mandumpala Devassy, B.; Edelbauer, W.; Greif, D. 2015. Numerical simulation of the effect of 3D needle movement on cavitation and spray formation in a Diesel injector, 9th International Symposium on Cavitation (CAV2015) Journal of Physics: Conference Series 656. http://doi:10.1088/1742-6596/656/1/012092. 
4. Wloka, J.; Pflaum, S.; Wachtmeister, G. 2010. Potential And Challenges of a 3000 Bar Common-Rail Injection System Considering Engine Behavior and Emission Level, SAE Technical Paper 2010-01-1131. 13 p. https://doi.org/10.4271/2010-01-1131.

5. Shinohara, Y.; Takeuchi, K.; Herrmann, O. E. 2011. 3000 bar common rail system, MTZ worldwide 72(1): 4-8.

https://www.springerprofessional.de/en/3000-bar-common-rail-system/6428740.

6. Neusser H. J.; Kahrstedt, J.; Dorenkamp, R. 2013. The Euro 6 engines in the modular Diesel engine system of Volkswagen, MTZ worldwide 74(6): 4-10. https://www.springerprofessional.de/en/archive/journal/38313.

7. Chasos, C. A.; Christodoulou, C. N.; Karagiorgis, G. 2012. CFD simulations of multi-hole Diesel injector nozzle flow and sprays for various biodiesel blends, ICLASS 12th Triennial International Conference on Liquid Atomization and Spray Systems, Heidelberg, Germany, September 2-6.

http://www.ilasseurope.org/ICLASS/iclass2012_Heidelberg/Contributions/Paper-pdfs/Contribution1263_b.pdf.

8. AVL Fire 2009.: Manual. Austria: AVL List Gmbh. 589 $\mathrm{p}$.

9. Vimal, K. P.; Sumit, G. 2015. Study of nozzle injector performance using CFD, International Journal of Recent advances in Mechanical Engineering (IJMECH) 4(3): 153-160. http://doi:10.14810/ijmech.2015.4312.

10. Chiatti, G.; Chiavola, O.; Palmieri, F. 2007. Injector dynamic and nozzle flow features in multiple injection modeling, SAE paper 2007-24-038, 8th Int. Conference on Engines for Automobile, Capri, Naples, Italy. https://doi.org/10.4271/2007-24-0038.

11.Salvador, F. J.; Martinez-Lopez, J.; Caballer, M. 2013. Study of the influence of the needle lift on the internal flow and cavitation phenomenon in diesel injector nozzles by CFD using RANS methods, Energy Conversion and Management 66: 246-256. https://doi.org/10.1016/j.enconman.2012.10.011.

12. Vrublevskij, A. N.; Gricjuk, A. V.; Denisov, A. V. 2007. Results of non-motorized injector tests for twophase fuel injection, Internal Combustion Engines 2: 43 $-47$. http://www.kpi.kharkov.ua/archive/Dvs/2007_2/8.pdf.

13. Salvador, F. J.; Carreres, M. D.; Jaramillo MartinezLopez, J. 2015. Comparison of microsac and VCO diesel injector nozzles in terms of internal nozzle flow characteristics, Energy Conversion and Management. 103: 284-299. https://doi.org/10.1016/j.enconman.2015.05.062.

14. Grishin, Y. A.; Kopylov, A. S. 2015. Numerical simulation of the fuel flow in the flow passage of the injector nozzle, Izvestiya vysshih uchebnyh zavedenij, Mashinostroenie 10(607): 31-37. http://izvuzmash.ru/articles/1217/1217.pdf.

15. Dabiri, S.; Sirignano, W. A. 2007. Cavitation in an orifice flow, Physics of fluids 19. https://doi.org/10.1063/1.2750655.

16. Dular, M.; Stoffel, B.; Sirok, B. 2006. Development of a cavitation erosion model, Wear 261(5-6): 642-655. https://doi.org/10.1016/j.wear.2006.01.020.

17. Poguljaev, Ju. D.; Bajtimerov, R. M. 2014. Determination of the flow rates of the nozzle channels of nozzles for injectors of Diesel engines, Construction and road machines 4: 20-23.

www.sdmpress.ru/online/1120142641.pdf.

18. Bastawissi, H. A.-E.; Elkelawy, M. 2014. Investigation of the flow pattern inside a diesel engine injection nozzle to determine the relationship between various flow parameters and the occurrence of cavitation, Engineering 6: 923-935.

http://dx.doi.org/10.4236/eng.2014.613084.

19.Sun, Z.-Y.; Li, G.-X.; Chen, C.; Yu, Y.-S.; Gao, G.X. 2015. Numerical investigation on effects of nozzle's geometric parameters on the flow and the cavitation characteristics within injector's nozzle for a high-pressure common-rail di diesel engine, Energy Conversion and Management 89: 843-861.

https://doi:10.1016/j.enconman.2014.10.047.

20. Som, S.; Aggarwal, S. K.; El-Hannouny, E. M.; Longman, D. E. 2010. Investigation of nozzle flow and cavitation characteristics in a Diesel injector, Journal of Engineering for Gas Turbines and Power 132. http://dx.doi.org/10.1115/1.3203146.

21. Tahmasebi, E.; Lucchini, T.; D'Errico, G.; Onorati, A. 2015. Numerical simulation of Diesel injector internal flow field, Energy Procedia 82: 51 - 58. https://doi: 10.1016/j.egypro.2015.11.882.

22. Brusiania, F.; Falfaria, S.; Pellonia P. 2014. Influence of the Diesel injector hole geometry on the flow conditions emerging from the nozzle, Energy Procedia 45: 749-758.

https://doi: 10.1016/j.egypro.2014.01.080.

\section{O. Vrublevskyi, D. Levchenko}

\section{MODELING OF HYDRODYNAMIC PROCESSES IN HIGH-SPEED DIESEL INJECTOR NOZZLE}

S u m m a r y

This article presents importance of the injector nozzle geometry for performance and durability of diesel fuel system, quality of fuel spray and in-cylinder work mixture formation. Reviewed ways to improve its hydraulic characteristics. As prototype for investigation has used injector nozzle of the high-speed diesel 4DTNA1. The estimated volumetric models of the injector nozzle with two different flowing channels geometry was made. Got the results of the fuel flow modeling by CFD calculation. Carried out analysis of the diesel flow parameters in both geometries with searching ways to reduce hydraulic loses and cavitation erosion influence.

Keywords: diesel engine, injector nozzle, nozzles holes, hydrodynamics, CFD.

Received October 20, 2017

Accepted April 25, 2019 